\title{
A pesquisa sobre educação, juventude e política: reflexões e perspectivas $^{1}$
}

\section{Research on education, youth and politics: reflections and perspectives}

\section{La investigación sobre la educación, la juventud y la política: reflexiones y perspectivas}

\begin{abstract}
(i) Universidade de São Paulo - USP, São Paulo, SP, Brasil. kimi@usp.br
(ii) Doutor pela Universidade de São Paulo - USP, São Paulo, SP, Brasil. marcelo.daniliauskas@gmail.com
\end{abstract}

Resumo: O objetivo deste artigo é, a partir de uma revisão crítica de parte dos estudos brasileiros que tematizaram as relações entre educação, juventude e política, na última década, analisar o peso conferido aos processos educativos e a diferentes instâncias formativas, no desenvolvimento dos modos como os jovens se relacionam com a política. Além disso, interessam as tendências apontadas por esses estudos, no que diz respeito às modalidades de engajamento e participação entre os jovens, suas motivações e seus sentidos. Lança-se mão também dos dados de um estudo sobre o engajamento de jovens Lésbicas, Gays, Bissexuais, Travestis, Transexuais e Transgêneros (LGBT), tendo em vista problematizar potencialidades e limites da discussão sobre o engajamento político da juventude. Palavras-chave: juventude, educação, política, engajamento, militância, jovens LGBT

\footnotetext{
${ }^{1}$ Apoio: Coordenação de Aperfeiçoamento de Pessoal de Nível Superior (CAPES)
} 
Abstract: Through a critical review of Brazilian studies that sought to think about the links between education, youth and politics in the last decade, this article aims to analyze the importance of educational processes to the development of the ways through which young people deal with politics. Moreover, the article is interested on the tendencies shown by these studies regarding the modalities of engagement and participation among young people, as well as their motivations and meanings. Lastly, the results from a study on the involvement of Lesbian, Gay, Bisexual and Transgender (LGBT) youth are presented in order to reflect about the possibilities and limitations of the discussion on youth political engagement nowadays.

Keywords: education, youth, politics, engagement, militancy, LGBT youth

Resumen: El objetivo de este artículo es, a partir de una revisión crítica de los estudios brasileños que han tematizado la relación entre educación, juventud y política, en la última década, analizar la importancia de los procesos educativos y de las diferentes instancias formativas en el desarrollo de los modos como los jóvenes se relacionan con la politica. Además, se destaca el interés en las tendencias presentadas por esos estudios con respecto a las modalidades de involucramiento politico y de participación de los jóvenes, a sus motivaciones y a sus significados. Por último, se utilizan datos de un estudio sobre la participación de jóvenes Lesbianas, Gays, Bisexuales y Transexuales (LGBT) con el fin de problematizar las posibilidades y las limitaciones de la discusión sobre la participación política de los jóvenes en la contemporaneidad.

Palabras clave: educación, juventud, politica, involucramiento, militancia, jóvenes LGBT

\section{Introdução}

A participação política dos jovens não se faz no vazio cultural e histórico, mas em sociedades reais que carregam as marcas singulares de sua história e as dificuldades específicas de seu presente. No contexto das desigualdades sociais da sociedade brasileira, compreender como e por que os jovens brasileiros participam da construção e da decisão societárias põe em questão a forma como cada um reconhece-se como integrante desse conjunto tão desigual e como se vê implicado nos seus destinos. (Castro, 2008, p. 253)

O estudo das relações entre os jovens e a política não constitui exatamente uma novidade, embora a produção sobre o tema, no Brasil, ainda possa ser considerada modesta em diferentes áreas do conhecimento (Castro, 2008; Sposito, 2009a, 2009b). Nesse quadro, o presente artigo pretende contribuir para o adensamento da discussão em torno dos efeitos não apenas dos processos educativos sobre o modo como os jovens experienciam e concebem sua relação com a política, mas também dos sempre renovados desafios que vêm sendo 


\section{pro.posıções

http://dx.doi.org/10.1590/1980-6248-2016-0126

apresentados às novas gerações, em função das reconfigurações do espaço público e do papel do Estado, além da ampliação das demandas dos cidadãos em torno de "novas bandeiras".

Nesse sentido, seria impossível conceber o debate que será recuperado neste artigo, sem considerarmos que a última década, no mundo ocidental, foi marcada (i) por uma crise estrutural do capitalismo, que aumentou consideravelmente a instabilidade econômica, social e política e que, se não é claramente identificada por todos os grupos sociais, é pressentida e vivenciada por meio de transformações absolutamente concretas, como as reformas previdenciárias e a flexibilização dos direitos trabalhistas, que atingem especialmente os jovens; (ii) pelo fenômeno do alongamento da escolarização das novas gerações, que contrasta com suas reduzidas possibilidades de inserção profissional e mobilidade social ascendente via escola e trabalho; (iii) pelo comportamento, da população em geral, de desencantamento ou, pelo menos, de desconfiança em relação à eficiência das democracias representativas, cujo exemplo mais facilmente quantificável e generalizado em diferentes países é o aumento da taxa de abstenção nas eleições, mesmo em países em que o voto é obrigatório, como no Brasil.

No caso brasileiro, ainda é preciso considerar que assistimos, na última década, à inserção de setores pauperizados da população no mercado de trabalho formal, com acesso a crédito e ampliação das possibilidades de consumo, além da diminuição da miséria por meio de políticas de microcrédito, transferência de renda e valorização do salário mínimo. Tais mudanças teriam formado o que alguns autores denominam de "novo proletariado", constituído basicamente por jovens trabalhadores que acessaram o mercado formal de trabalho ao longo da "década lulista" (2003-2013), mas que padecem com baixa remuneração, alta rotatividade e más condições de trabalho. Esses jovens trabalhadores têm demonstrado uma insatisfação crescente com sua condição; em outras palavras, expressam descontentamento com sua curta trajetória de ascensão, o que pode estar na base, por exemplo, das chamadas "jornadas de junho", de 2013, quando os jovens foram às ruas movidos por diferentes e contraditórias bandeiras (Braga, 2013; Muxel, 2001, 2007; Singer, 2013; Souza, 2012).

Há uma tradição consolidada de pesquisas que se dedicaram a compreender como os indivíduos desenvolvem percepções, opiniões e posições sobre o mundo da política. Parte significativa dessa literatura destaca o protagonismo da família no processo de transmissão e assimilação dos comportamentos e opiniões sobre a política, constatação minimizada por 


\section{pro·posições \\ $e$-ISSN 1980-6248}

http://dx.doi.org/10.1590/1980-6248-2016-0126

outros autores que argumentam que as socializações primárias seriam "colocadas à prova" por renovados processos de socialização, sobretudo na juventude, sem negar, contudo, a importância do papel da família (Darmon, 2010; Gaxie, 2002; Ihl, 2002; Muxel, 1997, 2001; Muxel \& Percheron, 1988; Oppo, 2009; Percheron, 1987, 1993; Schmidt, 2000).

Portanto, a juventude seria o período no qual valores e práticas assimilados no âmbito familiar seriam confrontados com novas experiências, que podem ser vivenciadas tanto em um plano microssocial (relações interpessoais de amizade, relacionamentos afetivos, vínculos associativos e religiosos, etc.), como também pelos desafios macrossociais, materializados em determinadas conjunturas políticas, econômicas e sociais nas quais os jovens estão inseridos. Dito de outra forma, os jovens estariam em um momento no qual a influência familiar pode ser relativizada, em função do desejo de integração a outras esferas da vida social, tais como o grupo de pares, a escola, o trabalho, o matrimônio, e isso se desdobra em novos aprendizados e processos de ressocialização. $\mathrm{O}$ estudo das relações entre juventude e política exige que se lance luz sobre os efeitos de diferentes processos e instâncias educativas (família, escola, Igreja, redes associativas, trabalho), tendo em vista compreender qual seria seu peso sobre o desenvolvimento das posições e das ações políticas dos jovens.

Partindo desse amplo leque de questões, o objetivo central deste artigo é, a partir do diálogo com parte da produção brasileira sobre as relações entre educação, juventude e política, na última década ${ }^{2}$, analisar o lugar conferido aos processos educativos e às diferentes instâncias formativas no desenvolvimento dos modos como os jovens se relacionam com a política. Além disso, interessam-nos as tendências apontadas por esses estudos, no que diz respeito às modalidades de engajamento e participação dos jovens, suas motivações e seus sentidos. Finalmente, lançaremos mão da apresentação de alguns aspectos de um estudo sobre o engajamento e a participação de jovens Lésbicas, Gays, Bissexuais, Travestis, Transexuais e Transgêneros (LGBT), tendo em vista problematizar algumas tendências que serão apresentadas a partir da produção bibliográfica.

\footnotetext{
2 Para realizar a revisão optamos por consultar a Biblioteca Eletrônica do Scientific Eletronic Library Online (SciELo), entre 2005 e 2015, por meio das seguintes expressões de busca: "educação, jovens e política"; "educação, juventude e política”; “juventude e política” e “jovens e política”. Após a leitura dos textos, selecionamos aqueles que respondiam aos objetivos deste artigo, incluindo alguns outros considerados relevantes, em função do número de vezes em que foram citados nos artigos selecionados originalmente, totalizando 27 artigos, além de 3 livros, 2 teses de doutorado e 1 dissertação de mestrado.
} 


\section{pro.posıções \\ Educação, juventude e política: os contornos de uma estreita e complexa relação}

Em um primeiro momento, é preciso considerar que, de acordo com diversos autores, o "olhar adulto" sobre as relações entre juventude e política (na academia, nas organizações políticas ou no senso comum), em geral, é marcado por críticas de diferentes matizes e por um difuso sentimento de desconfiança. Essa percepção é tributária da ideia de que o engajamento juvenil constitui um comportamento ainda em formação, um devir, que precisa ser amadurecido. Ou seja, trata-se de um modo de articular juventude à política como um processo propedêutico, que, portanto, considera a juventude como uma etapa preparatória para a vida política, isto é, como um período de desenvolvimento de capacidades e atitudes para o exercício pleno da vida cívica, o que só ocorrerá na idade adulta. Assim, esse modo de conceber a relação entre os jovens e a política não considera as tramas e os desafios do cotidiano juvenil, nem tampouco sua capacidade de criar organizações e dinâmicas próprias de participação política (Boghossian \& Minayo, 2009; Carrano, 2006; Castro, 2009; Maheirie et al., 2013; Martins \& Dayrell, 2013; Sposito, 2000).

Além disso, é preciso considerar que, de modo geral, os estudos sobre a "condição juvenil", ao longo do século XX, inscreveram-se no interior de um espectro analítico que ia da percepção dos jovens como "motor de mudanças" da sociedade até como um grupo potencialmente perigoso ou ameaçador, em diferentes sentidos (Boghossian \& Minayo, 2009; Sposito, 2000). Evidentemente, nenhum dos dois "polos" de interpretação pode ser comprovado como regra absoluta, e no Brasil encontramos, a partir dos anos 1960, uma importante tradição de estudos que tende a relacionar os jovens a ideais políticos transformadores e utópicos, oriunda, sobretudo, da análise do papel dos estudantes na luta contra a ditadura militar (Abramo, 1994; Mortada, 2009; Sposito, 2010). Esse modo de conceber qual seria a postura "típica" dos jovens diante da política (de questionamento, interrogação, organização e luta por transformações sociais) redundou em um discurso generalizado, em diferentes setores da sociedade e até mesmo no interior do meio acadêmico, de que na atualidade os jovens estariam desinteressados da política e progressivamente mais aderentes a projetos e valores individualistas, sobretudo ao sucesso pessoal, o que guardaria relação com a expansão da ideologia neoliberal, sua concepção de sociedade e de organização 


\section{pro·posıções

do Estado. Assim, tendo como referência uma suposta geração anterior formada por jovens engajados, o debate em torno da participação e/ou do interesse juvenil sobre a política, desde os anos 1980, se desenvolveu sob a sombra do "fatalismo" diante de sinais de uma "juventude alienada".

No entanto, as pesquisas empíricas e o debate teórico mais recentes tendem a apontar que, menos que "desinteressados" ou "apáticos" diante da política, os jovens se mostram, sobretudo, desiludidos com a "política tradicional" ou com os mecanismos institucionalizados da vida política nas sociedades democráticas, o que implica, por exemplo, em uma certa descrença em relação às eleições, aos partidos e aos homens políticos. Essa estrutura de representação política vem sendo apontada por jovens de diferentes países como incapaz de assimilar e responder às demandas concretas apresentadas pela sociedade, o que desestimularia o engajamento nas organizações políticas ditas "tradicionais" (partidos, sindicatos, movimento estudantil). Ademais, algumas pesquisas indicam que não seria a falta de informação que conduziria ao afastamento dos jovens das questões políticas, e sim o conhecimento e a rejeição consciente de determinadas práticas típicas da política institucional, além do aumento de interesse desses pela "política do cotidiano", levada a cabo por pequenas organizações, grupos informais, especialmente ligados à área cultural (Boghossian \& Minayo, 2009; Borelli, Rocha, Oliveira, \& Lara, 2009; Castro \& Nascimento, 2013; Dayrell, Gomes, \& Leão, 2010; Florentino, 2008; Fuks, 2011; Sposito, 2009a, 2009b, 2010).

Assim, autores apontam ser necessário que a análise da participação juvenil dialogue com as condições efetivas para a existência desse engajamento: em quais circunstâncias sociais e econômicas os jovens podem exercitar sua participação política? Existem estímulos, por parte da sociedade, do Estado, da família ou da escola, para tal exercício? Isso porque se acredita que um dos motivos possíveis da frágil participação social e política da juventude pode ser creditado à falta de espaços e de situações para o exercício e a aprendizagem da vida coletiva e da participação social, experimentação essa que poderia demonstrar aos jovens os resultados concretos das ações coletivas. E, sendo assim, não podemos esquecer que falar de juventude sempre significa falar de juventudes, no plural, uma vez que essa experiência fica condicionada a determinadas condições de ordem social/econômica (origem e classe social de pertencimento), cultural e geográfica (etnias, identidades religiosas, tradições culturais, valores 


\section{pro.posıções}

http://dx.doi.org/10.1590/1980-6248-2016-0126

e moralidades) e também de gênero (Dayrell, 2003; Dayrell et al., 2010; Miranda \& Freitas, 2013).

No mesmo sentido, é preciso sublinhar que a ação política não pode ser tomada como "algo natural, nem imediato". Resultado da interação de vários processos, a militância política resulta de socializações que predisponham à participação, seja na família, na escola, em espaços associativos ou organizações políticas, o que exige

uma análise que explore, ao mesmo tempo, a presença de disposições para a militância e sua conformação ao longo do tempo, ... assim como as condições objetivas que, definindo o espaço de possibilidades das interações, permitiram a ativação dessas disposições, produzindo ações efetivas num espaço social específico. (Moreno \& Almeida, 2009b, p.132)

A análise dos efeitos dos processos educativos sobre os modos como os jovens se relacionam com a política nos coloca, portanto, o desafio de compreender os variados processos de formação que redundam em um conjunto de predisposições ao interesse por assuntos de caráter político, à participação ativa como cidadão ou ao engajamento e à militância em torno de causas coletivas.

Como dito anteriormente, esse processo de formação tem seu primeiro momento no âmbito familiar, que continua sendo um espaço privilegiado de formação de valores e condutas sobre a vida como um todo e também sobre o mundo da política. Fuks e Pereira (2011), por exemplo, em seu estudo sobre o desenvolvimento de determinadas capacidades e competências políticas, destacam que o simples acesso a informações não é suficiente para criar disposições à participação ou mesmo para desenvolver um corpus coerente de conhecimentos sobre o mundo da política.

O diferencial do ambiente informacional que confere aos jovens a capacidade de articular conceitualmente o seu entendimento sobre política é a participação no dia a dia em conversas sobre política. A valorização da política como espaço de engajamento intelectual e comportamental, na esfera doméstica e suas redes, é elemento distintivo do ambiente familiar em que é socializado o jovem que tem refinamento político. (p.140)

Ainda de acordo com esses autores, a identificação do grau de escolaridade dos indivíduos como principal determinante do conhecimento sobre política constituiu um dos poucos consensos no debate sobre comportamento político. No entanto, em consonância com outros estudos, os autores chamam atenção para o fato de que o ambiente escolar 


\section{pro·posıções \\ $e$-ISSN 1980-6248}

http://dx.doi.org/10.1590/1980-6248-2016-0126

representa um fator definidor da quantidade e da qualidade do conhecimento sobre política, ou seja, novamente, como na família, o simples acesso à escolarização ou mesmo a informações sobre o mundo da política não é suficiente para formar jovens interessados e engajados na política. $O$ ambiente escolar precisa criar oportunidades concretas de participação dos alunos em diferentes tipos de atividades e iniciativas de caráter coletivo, que estimulem o debate e a vivência democrática, o que envolve uma dada concepção curricular e pedagógica que privilegia o protagonismo do aluno (Fuks, 2012; Fuks \& Pereira, 2011; Martins \& Dayrell, 2013; Miranda \& Freitas, 2013; Zibas, Ferreti, \& Tartuce, 2006).

Para além da família e da escola, é preciso considerar também o fato de que, crescentemente, as mídias vêm ganhando importância como meio de informação, discussão, e até mesmo de estruturação de identidades individuais e coletivas, criando novos espaços de engajamento político via redes sociais (Borelli \& Oliveira, 2010; Coutinho \& Safatle, 2009; Fernandes-Jesus, Cicognagni, \& Menezes, 2014).

Finalmente, vale destacar que a bibliografia revisada indica pouca sensibilidade do mundo adulto e de suas instituições à criação de espaços institucionais que estimulem a participação dos jovens e o desenvolvimento de valores democráticos. A escola, como se afirmou anteriormente, é um dos espaços privilegiados para o processo de aprendizagem de formas e mecanismos de participação. No entanto, a instituição escolar, tanto a pública quanto a privada, não tem priorizado a questão da participação como uma dimensão importante do processo educativo vivenciado pelos jovens e nem mesmo os tem informado a respeito da existência dessas instâncias. Uma resposta fácil diante desses dados é atribuir o problema aos alunos, considerando-os desinteressados ou apáticos. No entanto, diferentes pesquisas indicam que, quando a escola oferece atividades que exigem participação ativa para além dos estudos, os alunos e as alunas apresentam alto grau de envolvimento (Castro, 2009; Castro \& Nascimento, 2013; Dayrell, 2003; Martins \& Dayrell, 2013).

No que tange às "modalidades de participação" dos jovens e suas motivações, os dados das pesquisas brasileiras apontam tendências muito similares às pesquisas internacionais: os jovens se sentem motivados a se engajar em ações coletivas na esfera pública, quando essas se orientam por temas de ordem prática e em coerência com suas experiências e demandas cotidianas e concretas: a violência, a empregabilidade e a melhoria das condições do ensino (Carrano, 2006). Assim, os jovens parecem estar mais atraídos por mobilizações de caráter 


\section{pro.posıções

http://dx.doi.org/10.1590/1980-6248-2016-0126

pontual, caracterizadas por um "engajamento fluido", tendo em vista alcançar resultados imediatos, sobretudo lançando mão de manifestações públicas organizadas, em geral, por meio das redes sociais (Muxel, 2007; Singer, 2013). Vale destacar ainda que, na contramão da maioria dos jovens, há grupos juvenis militando em várias organizações pertencentes aos campos identificados como "esquerda" e "direita", inclusive em organizações cujo engajamento exige muito desses jovens em termos de disciplina e comprometimento em todos os aspectos de suas vidas. Embora se trate de fenômeno minoritário, ele não pode ser ignorado, pela sua capacidade de renovação e continuidade e também porque lança luzes para a compreensão de outras modalidades do engajamento juvenil (Brenner, 2011; Lugó, 2014).

Uma tendência da participação juvenil que se destaca nos estudos diz respeito ao desenvolvimento de ações e espaços relacionados às artes e à cultura, mas também aos esportes e à religião. De acordo com Carrano (2006), “os grupos de orientação religiosa, esportiva, e artísticas constituem o substrato do associativismo juvenil no Brasil de hoje. Esses grupos constituem significativa sociedade civil juvenil que articula ações coletivas nem sempre reconhecidas como políticas ou socialmente relevantes" (p. 4).

Nesse mesmo sentido, outros autores apontam para a necessidade de considerar o surgimento de um "novo fazer político", que implica ter em conta, nas análises, os novos sentidos dados ao político, bem como as subculturas juvenis emergentes e sua influência sobre espaços comunitários, escolas e diferentes tipos de coletivos juvenis, inclusive de voluntariado (Borelli \& Oliveira, 2010; Castro, 2008; Facchini, 2011; Iriart \& Bastos, 2007; Moreno \& Almeida, 2009b; Sposito, 2000; Weller, 2005).

Assim, poderíamos dizer que, se é possível observar tendências gerais nas atitudes e nos comportamentos "característicos" de uma certa idade e/ou etapa da vida, como a atual disposição dos jovens ao "engajamento pontual", é improvável distinguir efeitos "puros da idade". Há consenso, entre os principais estudos das áreas de sociologia da juventude, sociologia das gerações e de socialização política, de que a idade é uma variável-chave para a compreensão dos fenômenos políticos, na medida em que, por meio dela, pode-se introduzir nos estudos o parâmetro do tempo e, portanto, das transformações da experiência individual e coletiva ao longo da existência humana. Entretanto, o peso que diferentes idades e/ou etapas de vida exercem sobre a estruturação de fenômenos e de comportamentos políticos não suscita regularidades infalíveis ou mesmo lógicas facilmente identificáveis (Muxel, 2001). 


\section{pro.posıções \\ $e$-ISSN 1980-6248}

http://dx.doi.org/10.1590/1980-6248-2016-0126

No mesmo sentido, os estudos que tratam especificamente das diferentes modalidades de engajamento político também tendem a apontar que uma propriedade social, seja ela qual for (idade, gênero, renda, status profissional, escolarização), não tem considerável capacidade explicativa, se não for analisada em uma dada configuração, na qual ela se atualiza e contribui para a formação de determinadas disposições ao engajamento ou à participação política: "É na sucessão de encontros entre as propriedades sociais e os contextos variáveis de socialização que se formam as disposições" (Filieulle \& Pudal, 2010, p.173). Dito de outra forma, assim como as análises sobre o modo como os jovens se relacionam com a política não podem se pautar tão somente por uma suposta especificidade da experiência juvenil em si, tampouco a análise e a compreensão do engajamento político podem se dar sem a construção de um quadro analítico que leve em consideração diferentes variáveis, sobretudo (i) os atributos pessoais dos militantes, (ii) a organização do campo político em si e também (iii) o modo como funcionam as instituições e os movimentos políticos (hierarquia, repertório de ação, recrutamento e formação de quadros).

Assim, neste artigo partimos da premissa de que uma discussão que tematize a relação entre educação, juventude e política pressupõe que o modo como cada grupo se envolve com questões de ordem política depende da especificidade de diferentes configurações, nas quais muitos elementos de análise entram em cena: o período histórico; a conjuntura social e política; o pertencimento dos indivíduos em questão a uma dada classe social (e a consequente submissão a certas condições de existência material e simbólica); o gênero; o nível de escolarização; a vivência de determinadas modalidades de socialização; bem como os efeitos da idade e das etapas de vida.

\section{Engajamento e participação política entre jovens LGBT}

Diante das tendências e dos desafios apontados anteriormente em relação à produção bibliográfica que articula juventude, política e educação e partindo da premissa expressa acima, pensamos ser produtivo discutir alguns aspectos de um estudo empírico sobre a relação entre os jovens e a política que lança luz sobre um tipo de participação e militância juvenil ainda pouco explorado, segundo Sposito (2009a, 2009b), e que, apesar de sua especificidade, guarda 


\section{pro.posıções \\ $e$-ISSN 1980-6248}

http://dx.doi.org/10.1590/1980-6248-2016-0126

também traços comuns com as experiências contemporâneas dos jovens no mundo da política e com suas angústias e demandas de ordem pessoal e coletiva.

Trata-se de um estudo sobre o engajamento de jovens LGBT, desenvolvido no quadro de um doutoramento concluído em março de 2016 (Daniliauskas, 2016). A pesquisa teve como objetivo analisar a emergência de grupos organizados de jovens LGBT e os processos de engajamento de seus membros. Para tanto, foram realizadas entrevistas semiestruturadas com fundadores(as) e coordenadores(as) de grupos jovens, bem como observação das atividades desenvolvidas pelas entidades, entre 2012 e 2014, o que nos permitiu problematizar e descrever o contexto de emergência desses grupos, seus modos de organização e funcionamento, suas bandeiras de luta e formas de ação, tal como o perfil e o processo de engajamento de seus participantes e militantes. Na tese, foi traçado um panorama histórico envolvendo as seguintes organizações jovens LGBT atuantes nas cidades de São Paulo e Paris: Projeto de Apoio a Gays e Lésbicas Adolescentes (PAGLA), E-jovem, XTeens, Jovens e Adolescentes Homossexuais (JA) e Projeto Purpurina, MAG - Jeunes LGBT, Pôle Jeunesse, CONTACT e Le Refuge.

Todas essas organizações promovem encontros de apoio mútuo, on-line e off-line (presenciais e virtuais), voltados para jovens cujas idades variam entre 13 e 30 anos e por eles organizados. Assim, as organizações e as associações juvenis LGBT analisadas são caracterizadas por serem agrupamentos de, para e por jovens, ou seja, seus participantes e suas ações têm em conta as demandas desse público, e a coordenação e o funcionamento são levados a cabo por meio da participação dos próprios jovens. Em função das demandas e das necessidades específicas desses jovens, a ação dos grupos privilegia atividades que visam à autoaceitação, à resolução de problemas familiares, à possibilidade de constituir espaços de dignidade e respeito à diversidade sexual na escola, no trabalho e na vida pública.

Em alguns grupos, foi possível ainda identificar diferentes níveis de interlocução com o poder público e/ou de atuação. Como a maioria dos jovens, esses também têm ressalvas em relação à política institucional, materializada em "gestões", partidos, eleições ou espaços institucionalizados de participação. Portanto, vale destacar que os jovens LGBT tendem a assumir que "fazer política" significa, sobretudo, promover transformações sociais a partir de suas vidas cotidianas e no interior dos espaços pelos quais circulam, o que, eventualmente, 


\section{pro.posıções

http://dx.doi.org/10.1590/1980-6248-2016-0126

pode passar por reivindicações e demandas pontuais em relação a diferentes esferas do Estado, por meio da formulação de legislações, políticas ou serviços públicos específicos.

Para a discussão que apresentaremos neste artigo, destacaremos uma das organizações estudadas, mais especificamente, uma rede de jovens LGBT, o E-jovem, um dos primeiros grupos a se constituir e a primeira rede nacional de jovens LGBT no Brasil, que permanece ativa até os dias atuais. De modo geral, todos os grupos com atuação em São Paulo passaram, ao longo de sua trajetória, por três "fases": a) fase on-line: marcada pela formação de comunidades somente virtuais, uso de pseudônimos e total anonimato de seus participantes; b) fase da "vontade de estar juntos(as)": vivenciada como uma transição entre a segurança e o anonimato do ambiente on-line e os primeiros passos rumo à ocupação do "espaço público" e à estruturação de organizações no ambiente off-line; c) fase do reconhecimento público e de estratégias de expansão: período de estruturação dos grupos em redes, com significativo aumento do número de participantes e de parcerias e articulações com o movimento e as organizações LGBT “adultas”, além de uma inflexão importante em relação ao modo como os grupos concebiam partidos políticos, governos, políticas públicas e os espaços institucionalizados de participação política, como conferências e conselhos municipais, estaduais e nacionais.

A trajetória da rede E-jovem, que também atravessou essas fases, está intrinsicamente relacionada com o início da comercialização da Internet no Brasil, a partir da segunda metade dos anos de 1990. A rede foi fundada, no final daquela década, por Deco, pseudônimo de um jovem universitário que na época tinha aproximadamente 26 anos e ainda estava em processo de autoaceitação, isto é, não havia assumido publicamente sua homossexualidade, nunca havia namorado nem saído para estabelecimentos de frequência gay e fazia uso da Internet para buscar informações e encontrar seus pares, outros jovens com inquietações e conflitos a respeito de sua sexualidade.

Nessas incursões pela rede mundial, o entrevistado conheceu um programa de chat [bate-papo online], o mIRC, que permitia aos(às) usuários(as) a criação de salas temáticas de bate-papo, o que levou à formação de alguns canais gays: \#Gay Brasil, \#Gay SP, \#Gay Rio (assim, sucessivamente, por estados). O \#Gay Brasil era o mais utilizado, de modo geral, mas foi criado também o \#Gay Jovem, específico para esse público. Nesse período, os usuários utilizadores das salas de bate-papo, normalmente, utilizavam pseudônimos ou apelidos na 


\section{pro·posıções

Internet, mas tal prática era ainda mais frequente entre pessoas LGBT, incluindo os jovens, como forma de manter o anonimato, a privacidade de suas identidades off-line, sobretudo por conta do estigma social atrelado às identidades e, por consequência, às experimentações afetivo-sexuais das pessoas LGBT.

Deco passou a ser um frequentador assíduo do canal \#Gay Jovem e fez amigos(as)nesse espaço on-line. Com o passar do tempo, ele e outros moderadores do \#Gay Jovem perceberam que grande parte dos jovens procurava o canal porque estava em conflito ou queria entender sua sexualidade, e as perguntas eram quase sempre as mesmas: "Será que sou gay? ", "Como assumir isso?", "Como contar para os amigos? ", "Como contar para a família? ", "Estou apaixonado pelo meu amigo na escola, o que eu faço? ". Então esse grupo de participantes do bate-papo \#Gay Jovem teve a ideia de criar um site de referência, com uma espécie de FAQ [Frequently Asked Questions], ou seja, de respostas às Perguntas Mais Frequentes. O site deveria se chamar G-Jovem, por conta do canal de origem, mas houve dificuldades para levar a cabo o projeto, em função da pouca experiência em desenvolvimento de websites; assim, o projeto não saiu do papel.

Apesar de o grupo ter desistido da proposta inicial, Deco buscou meios de levar adiante o empreendimento e conheceu, por meio da rede mundial de computadores, um adolescente de 15 anos que possuía conhecimentos em desenvolvimento de sites web; logo passaram a trabalhar juntos, mas virtualmente, sem nunca terem se conhecido pessoalmente, apesar de morarem na mesma cidade, Campinas, o que nos permite vislumbrar como era forte o receio da exposição de suas identidades em função da discriminação. E assim surgiram, em 2001, um site e uma lista de discussão com o nome de E-jovem, fazendo alusão aos jovens "conectados" que estavam buscando seu lugar no ciberespaço, nas suas vidas cotidianas e no mundo, em um processo de experimentação de como lidar com sua sexualidade LGBT. As ferramentas on-line desenvolvidas pelo E-jovem contribuíram para a formação de um grupo coeso de pessoas que, com o passar o tempo, foram se aproximando, tornando-se amigas, e até flertes virtuais começaram a surgir. Não tardou muito para que, em 2002, com a intensificação dos laços no ambiente on-line, esses jovens decidissem se encontrar pessoalmente. E os relatos dos encontros passaram a circular nas listas de discussão, estimulando e encorajando novas reuniões presenciais. 


\section{pro·posıções \\ $e$-ISSN 1980-6248}

http://dx.doi.org/10.1590/1980-6248-2016-0126

Com os encontros presenciais já em curso, surgiu a ideia de realizar uma primeira atividade: jovens da região de Campinas e da Grande São Paulo, coordenados por Deco, decidiram realizar um filme caseiro. Intitulado Meu cachorro gay, o filme foi inscrito na categoria "produção amadora" do Festival Mix Brasil de Diversidade Sexual ${ }^{3}$. Esse primeiro trabalho coletivo off-line, além de marcar a ampliação de atuação do grupo para além do virtual, também expressa uma característica geral dos coletivos juvenis: o interesse por atividades de cunho cultural (Almeida, 2013).

O E-jovem passou, então, a estimular a realização dos encontros off-line e também de núcleos presenciais em diferentes localidades, que ficaram conhecidos como E-grupos. Em 2013, o E-jovem contava aproximadamente 22 E-grupos espalhados por 11 estados brasileiros. Além disso, a partir de 2003, o E-jovem e seus E-grupos passaram a dialogar e atuar em entidades "adultas" do movimento LGBT. Fruto dessa interação, a rede E-jovem decidiu se formalizar legalmente como Organização Não-Governamental (ONG). Um dos motivos importantes por trás dessa decisão foi a preocupação com a expansão e a democratização do acesso ao grupo, na medida em que a Internet naquela época ainda estava restrita a uma reduzida parcela da população, que excluía os jovens LGBT das classes populares. Os encontros presenciais, portanto, para além da sociabilidade, seriam um meio de divulgação e de agregação de novos membros que não estavam virtualmente conectados e pertenciam a outras camadas sociais. Apesar do incentivo e da valorização dos encontros e dos espaços presenciais, a rede continuou investindo também nas relações virtuais, aproveitando a fase de popularização do acesso à Internet no Brasil ao longo da primeira década do novo século. Assim, em 2008, o E-jovem criou o E-kut, que aludia à rede social Orkut, da Google, oferecendo a possibilidade de elaboração de um perfil pessoal, criação de comunidades virtuais e a ferramenta de bate-papo, garantindo aos jovens privacidade e possibilidade de interação virtual e, posteriormente, presencial.

Nesse mesmo período, em algumas localidades, os E-grupos passaram a atuar diretamente na organização das Paradas do Orgulho LGBT em suas respectivas cidades, ampliando o escopo de ação da recém-formada rede nacional e unindo-se a importantes manifestações políticas de massa, o que confirma a tendência dos jovens, de diferentes grupos

\footnotetext{
3 Mostra de filmes voltados à temática da diversidade sexual que, desde 1993, ocorre anualmente em diversas cidades brasileiras.
} 


\section{pro.posıções \\ $e$-ISSN 1980-6248}

http://dx.doi.org/10.1590/1980-6248-2016-0126

sociais, a demonstrar suas reivindicações por meio de protestos públicos (Di Giovanni, 2003; Simões \& Fachini, 2009). Além disso, a rede realizou, em 2004, seu primeiro encontro nacional e, em 2012, aproveitou a Marcha Nacional Contra a Homofobia para se apresentar publicamente em Brasília e para reunir os e-grupos de todo o País em torno de um evento de caráter político mais amplo. A rede ainda empreendeu esforços para constituir projetos de cunho educativo e/ou voltados à escola: a Escola Amiga, os Gládios e a Escola Jovem $\mathrm{LGBT}^{4}$.

Para analisar os processos de engajamento e as trajetórias de militância desses jovens, é preciso recuperar algumas questões fundamentais: o Movimento LGBT se constituiu a partir do combate ao preconceito e à discriminação em relação a uma ordem social heterossexista ${ }^{5}$, ou seja, busca reconhecimento e igualdade social e política para outras possibilidades de relações afetivo-sexuais para além da heterossexualidade. $O$ heterossexismo, em nossas sociedades, manifesta-se de modo contundente em diferentes instâncias de socialização - a família, a escola, o trabalho, o bairro, as Igrejas. E não seria exagero afirmar que as principais delas, primárias e secundárias, em geral, se apoiam na premissa da heterossexualidade compulsória, o que se desdobra em preconceito e discriminação em relação àqueles que não se enquadram nessa norma. É nessa conjuntura que os jovens LGBT se deparam com a realidade na qual não são aceitos, são hostilizados e não podem expressar seus questionamentos sobre determinados temas, como identidades de gênero e sexualidades. Como uma potencial

\footnotetext{
${ }^{4}$ A iniciativa da Escola Amiga propõe que os E-jovens levem um termo de adesão à direção ou à coordenação de sua escola, que pode se comprometer a respeitar os direitos LGBT e ganhar o "selo de Escola Amiga", ou seja, não discriminatória e amigável com os(as) jovens LGBT. Os Gládios têm inspiração nos Gay-Straight Alliances (Alianças entre Héteros e Gays - GSA) dos Estados Unidos, que são grupos de interesse, às vezes chamados de "clubes", formados nas escolas estadunidenses por jovens LGBT e seus "aliados heterossexuais", conhecidos(as) também pelo termo "simpatizantes" da luta pelos direitos das minorias. Finalmente, em 2010, foi criada a primeira Escola Jovem LGBT do Brasil. A viabilização desse projeto foi possível porque a rede se inscreveu e foi selecionada por um edital realizado pelo Ministério da Cultura em parceria com a Secretaria de Cultura do Estado de São Paulo para a criação de Pontos de Cultura, com financiamento governamental. Os principais objetivos da Escola Jovem eram: proporcionar um ambiente em que cada um possa ser quem é, sem restrições, por meio de um espaço de sociabilidade, aliado a aulas e oficinas profissionalizantes de difusão da cultura jovem LGBT, como: expressão gráfica (fanzine, revista e literatura); expressão artística (dança, música e drag-queen); e expressão cênica (webtv, teatro e cinema), para que os jovens encontrassem meios de se expressar, transmitir suas questões, angústias e demandas para um público mais amplo que as próprias pessoas LGBT. Com o fim do financiamento do edital em 2013, a Escola Jovem foi progressivamente se desarticulando.

5 "Um sistema em que a heterossexualidade é institucionalizada como normal social, política, econômica e jurídica, não importa se de modo explícito ou implícito. Uma vez institucionalizado, o heterossexismo manifestase em instituições culturais e organizações burocráticas, tais como a linguagem e o sistema jurídico. Daí advêm, de um lado, superioridade e privilégios a todos que se adéquam a tal parâmetro e de outro, opressão e prejuízos a lésbicas, gays, bissexuais, travestis, transexuais e até mesmo a heterossexuais que porventura se afastem do padrão da heterossexualidade imposto" (Rios, 2009, pp. 62-63).
} 


\section{pro·posıções

identidade/sexualidade LGBT, em geral, não é bem recebida nesses espaços, os jovens sentem-se motivados a buscar seus pares de diferentes modos, como discutimos anteriormente. Poderíamos dizer que as disposições para o engajamento nos grupos LGBT são construídas nesses espaços de socialização não pelo estímulo à participação juvenil, mas pela necessidade desses jovens de compartilhar seu sofrimento moral e psíquico e buscar apoio para enfrentar a discriminação que é gestada nas próprias instâncias de socialização.

Os grupos organizados de jovens LGBT oferecem não apenas acolhimento e espaço para discutir a rejeição e os conflitos vivenciados nas principais esferas socializadoras nas quais os jovens estão inseridos, mas também uma possibilidade de ressocialização via afirmação da identidade LGBT, o que passa pela minimização do sofrimento e da angústia de sentir-se "diferentes" em uma ordem social heterossexista. Isso quer dizer que a dor individual encontra um lugar de expressão na luta contra a homofobia, concretizada em ações coletivas no interior de um movimento social e político. E, nesse movimento, um profundo processo de ressocialização é vivenciado pelos jovens que participam ou militam nos grupos LGBT, visto que a superação da condição de sofrimento e angústia causados pela discriminação exige rompimentos importantes com os valores assimilados na família e mesmo na escola.

Finalmente, vale destacar, em consonância com a discussão anterior sobre os novos sentidos que os jovens atribuem ao político, que os jovens LGBT desejam lutar contra a homofobia e transformar as relações sociais, sobretudo no plano microssocial, notadamente na família, com amigos, na comunidade, na escola e no trabalho, tendo em vista uma forma de "reconciliação" com esses espaços, nos quais desejam ser respeitados; e esperam conscientizar as pessoas para o acolhimento futuro de outros jovens LGBT, rompendo, assim, o ciclo do heterossexismo. Em suma, as organizações juvenis LGBT não só promovem uma ressocialização em relação às principais esferas de socialização primária e secundária, mas, ao mesmo tempo, fazem delas os principais alvos de suas intervenções. Como discutido por meio da revisão bibliográfica, a juventude é um período privilegiado de adaptação e transformação dos valores adquiridos, sobretudo, no âmbito familiar, o que não implica em um total distanciamento ou negação dessa instância. Mesmo nos casos em que jovens LGBT foram vítimas de violência, há um desejo importante de reconciliação e investimento de esforços para que a relação com a família possa ser transformada com base na aceitação de sua condição LGBT. 


\section{pro·posıções

A propósito, vale destacar que a rejeição familiar é um conflito recorrentemente relatado pelos jovens engajados em grupos LGBT, o que parece perpassar núcleos familiares de diferentes estratos sociais, econômicos e educacionais. Assim, não seria exagero afirmar que a sexualidade é um foco de tensão tão central que os grupos analisados nesta pesquisa, de modo geral, reúnem jovens LGBT com diferentes condições socioeconômicas, o que, evidentemente, não quer dizer que a origem e a posição sociais não exerçam influência sobre o modo de inserção desses jovens nos grupos e sobre suas trajetórias como militantes, por meio da constituição de diferentes redes de afinidades e amizades e da ocupação de cargos nas entidades.

Como se trata de um movimento de jovens, sua maioria ainda frequenta a escola ou está no início do Ensino Superior, e, como essas instituições também são marcadas pela homofobia, os movimentos de jovens LGBT, em especial o E-jovem, demonstram grande preocupação com a transformação da escola em um espaço de discussão, aceitação e respeito aos jovens LGBT, o que se materializa em projetos como a Escola Amiga, os Gládios e a Escola Jovem LGBT e na luta pela inclusão das temáticas de gênero e sexualidade nos planos de Educação municipais, estaduais e federal.

Interessante notar, ainda, que o fato de instâncias de socialização, como a família e a escola, raramente incentivarem a participação juvenil em questões políticas, como a bibliografia sobre o tema aponta, não significa que os conflitos vivenciados - inclusive pela ausência da possibilidade do debate - no seu interior não constituam, em si mesmos, uma espécie de motivação para o engajamento em ações e causas coletivas, como no caso dos jovens LGBT. Essas motivações iniciais, pautadas na dor e no sofrimento da discriminação, atingem outro patamar de potencialidade política no encontro com jovens na mesma condição e, sobretudo, no encontro com grupos já organizados em torno da luta contra a homofobia e o heterossexismo. Assim, para além das motivações, das necessidades individuais e das especificidades dessas trajetórias, é preciso considerar, na análise dos processos de engajamento dos jovens LGBT, também as características do grupo com o qual eles se encontram e se afinam e suas relações com o mundo da política e os investimentos diretos ou indiretos com outros grupos políticos, inclusive político-partidários. Ou seja, o modo como um movimento social ou político se organiza depende da interação com a conjuntura política 


\section{pro·posıções \\ $e$-ISSN 1980-6248}

mais ampla, com outras iniciativas que estão em andamento por meio das organizações políticas já existentes (Moreno \& Almeida, 2009a).

No que tange especificamente às modalidades de engajamento ou aos percursos mais típicos dos jovens no interior dos grupos LGBT, poderíamos dizer que os jovens se dividem em dois grupos: a) uma minoria que procura inicialmente as organizações com o desejo prévio de se envolver, participar e militar contra a homofobia; e b) uma maioria formada por aqueles que buscam os grupos juvenis LGBT para obter apoio, suporte, informações e encontrar amigos. Nesse segundo grupo, o engajamento não ocorre imediatamente: é um processo que começa com a participação em atividades promovidas pelo grupo, o conhecimento de sua estrutura, de seus membros e até a averiguação de sua idoneidade e eficácia, para, paulatinamente, passar à colaboração nas atividades do grupo e, por fim, o oferecimento de apoio e suporte aos novos jovens LGBT recém-ingressados. Alguns dentre esses jovens, com o tempo, assumem cargos de coordenação.

Em que pese o fato de a rede ser, evidentemente, muito bem organizada e contar atualmente com uma estrutura considerável, o E-jovem, como todas as outras associações de jovens LGBT, enfrenta dificuldades para dar continuidade a determinadas ações, em função da alta rotatividade de seus participantes, que rapidamente percorrem a adolescência e parte da juventude e se deparam com o ingresso na universidade e/ou no mercado de trabalho e passam a ter cada vez menos tempo disponível para a atuação militante. Esse é um traço similar aos achados das pesquisas sobre a manutenção de grêmios estudantis e suas ações nas escolas brasileiras (Martins \& Dayrell, 2013; Zibas et al., 2006). Diante desse desafio, o Ejovem assumiu uma nova estratégia de prolongamento do engajamento e da atuação militante, por meio do estímulo para que os jovens LGBT mais experientes entrassem em partidos políticos e ocupassem espaços de participação e controle social de políticas públicas em âmbito municipal, estadual e federal, como, por exemplo, o Conselho Municipal de Saúde; o Grupo de Trabalho Estadual de São Paulo sobre DST/Aids; o Conselho Nacional de Juventude (CONJUVE); e o Conselho Nacional LGBT, além da participação em conferências como a Conferência Nacional de Educação (CONAE), a Conferência Nacional de Políticas LGBT, a Conferência Nacional de Juventude - as quais, antes de culminarem em suas etapas nacionais, passam por encontros municipais e estaduais. 


\section{pro·posıções \\ $e$-ISSN 1980-6248}

http://dx.doi.org/10.1590/1980-6248-2016-0126

Além dessa forma de participação institucional junto ao poder público, o E-jovem passou a incentivar que seus membros se filiem a partidos políticos, declarando-se oficialmente uma organização pluripartidária. Nesse quesito, a rede de jovens LGBT se diferencia de todos os outros grupos organizados de jovens LGBT analisados, pois todas as outras se declaram apartidárias, para evitar conflitos entre seus membros e para se proteger de um potencial cooptação ou associação excessiva a um partido político ou a governos específicos - o que poderia diminuir o grau de autonomia da entidade e também afastar novos ingressantes, dada a desconfiança dos jovens em relação às instituições políticas tradicionais, como partidos e governos.

Se, entre os jovens LGBT entrevistados, de fato, há uma grande desconfiança em relação a governos, partidos e políticos, de um modo geral, assim como apontam Carrano (2006) e Florentino (2008), os jovens não necessariamente rejeitam a política e o Estado em si mesmos, e até acreditam que, potencialmente, a política tradicional poderia garantir um melhor ordenamento da sociedade e promover qualidade de vida e segurança para as minorias ou os grupos minorizados. O que é, efetivamente, questionado diz respeito ao funcionamento dessas instituições, baseado em uma percepção de que a classe política se apropria da máquina estatal para seu proveito próprio e, em geral, demonstra baixa eficácia na resolução de conflitos e mazelas sociais e econômicas.

Por outro lado, vale destacar que, se a maioria dos grupos juvenis LGBT se apresenta como apartidária, o mesmo não acontece com seus membros: praticamente todos os jovens LGBT, em seus depoimentos, apresentaram algum tipo de identificação ideológica e partidária, variando de centro-direita a esquerda, sendo essa majoritária, pois há a percepção de que governos e partidos de esquerda são mais permeáveis às demandas LGBT, assim como de outras minorias ou grupos vulneráveis. Portanto, não poderíamos afirmar que a política não se encontre no horizonte desses jovens - apesar da rejeição ao funcionamento da política institucional e a da democracia representativa -, seja para a sua crítica, seja como alvo de suas intervenções. Assim avalia uma das coordenadoras do E-jovem:

Investir na política [institucional, incluindo os espaços de participação como conferências e conselhos de políticas públicas] é um desgaste de energia e de tempo, às vezes até um desperdício de recursos públicos, são muitas promessas e poucas realizações, mas ainda é melhor ocupar esses espaços do que deixá-los abandonados. Se ocupando a situação está ruim, seria ainda pior se não estivéssemos participando. 


\section{pro-posições \\ $e$-ISSN 1980-6248}

http://dx.doi.org/10.1590/1980-6248-2016-0126

O "caso" dos jovens militantes LGBT, em diálogo com a revisão bibliográfica, contribuiu para dar destaque aos eixos de análise que, pensamos, poderiam ser tomados como questões incontornáveis nas pesquisas sobre educação, juventude e política: (i) a influência da socialização primária na formação de determinadas disposições duráveis em relação à política; (ii) os processos de ressocialização que, posteriormente, possibilitarão a "adaptação" dos valores, das práticas e dos comportamentos assimilados no âmbito familiar e na escola a novas vivências e desafios, notadamente em experiências associativas e políticas; (iii) as características e feições assumidas pelos ditos "engajamentos pontuais" e pelos "novos sentidos do político" e seus efeitos sobre o modo como grupos de jovens se organizam em torno da defesa de causas coletivas; e, finalmente, (iv) a ambivalência dos sentimentos e das ações em relação à política institucionalizada e às formas "tradicionais" de militância.

Sem dúvida alguma, ainda há muito a ser pesquisado e discutido no que tange às complexas relações entre educação, juventude e política, sobretudo diante do desafio de compreender os novos sentidos atribuídos pelos jovens à política e a configuração de renovadas formas de engajamento e participação. E essa agenda de pesquisa exige também a interrogação, por meio de estudos quantitativos e qualitativos, sobre como as novas formas de relacionamento dos jovens com a política podem influir na organização e na reprodução das democracias representativas em diferentes países. Finalmente, em que pese o fato de que a bibliografia aponta que não só os jovens têm demonstrado desconfiança e desilusão com a política institucionalizada, cabe aos pesquisadores da juventude se perguntar sobre os ditos "efeitos tardios" dos processos de socialização e socialização política, tendo em vista incluir em nossas preocupações o impacto de determinadas experiências de participação ou engajamento juvenil sobre o comportamento político das futuras gerações de adultos. 


\section{pro-posıções \\ $e$-ISSN 1980-6248}

\section{Referências}

Abramo, H. W. (1994). Cenas juvenis: punks e darks no espetáculo urbano. São Paulo: Scritta.

Almeida, R. S. de. (2013, junho). Juventude, direito à cidade e cidadania cultural na periferia de São Paulo. Revista do Instituto de Estudos Brasileiros, 56, 151-172.

Boghossian, C. O., \& Minayo, M. C. de S. (2009). Revisão sistemática sobre juventude e participação nos últimos 10 anos. Saúde e Sociedade, 18(3), 411-423.

Borelli, S. H. S., \& Oliveira, R. de C. A. 2010, julho/setembro). Jovens urbanos, cultura e novas práticas políticas: acontecimentos estético-culturais e produção acadêmica brasileira (1960-2000). Utopía y Praxis Latinoamericana, 15(50), 57-69.

Borelli, S. H. S., Rocha, R. M. R., Oliveira, R. C. A., \& Lara, M. R. (2009). Jovens urbanos: ações estético-culturais e novas práticas políticas. Revista Latinoamericana de Ciencias Sociale, Niñez y Juventud, 7(1), 375-392.

Braga, R. (2013). Sob a sombra do precariado. In E. Maricato (Org.), Cidades rebeldes (ebook). São Paulo: Boitempo.

Brenner, A. K. (2011). Militância de jovens em partidos políticos: um estudo de caso com universitários. Tese de Doutorado em Educação, Universidade de São Paulo, São Paulo.

Carrano, P. (2006). Juventude e participação no Brasil: interdições e possibilidades. Democracia Viva, 30, 3-5.

Castro, L. R. de. (2008, junho). Participação política e juventude: do mal-estar à responsabilização frente ao destino comum. Revista de Sociologia Política, 16(30), 253-268.

Castro, L. R. de. (2009). Juventude e socialização política: atualizando o debate. Psicologia: Teoria e Pesquisa, 25(4), 479-487.

Castro, L. R., \& Nascimento, E. M. (2013, junho). Politizar as relações entre jovens e adultos? A construção da experiência escolar pelos estudantes. Estudos de Psicologia,18(2), $359-367$. 


\section{pro-posições}

http://dx.doi.org/10.1590/1980-6248-2016-0126

Coutinho, M., \& Safatle, V. L. (2009). A internet e as eleições municipais em 2008: o uso dos sítios eletrônicos de comunidades na eleição paulistana. Revista de Sociologia e Política, 17(34), 115-128.

Daniliauskas, M. (2016). Não se nasce militante, torna-se: processo de engajamento de jovens LGBT - Panorama histórico na cidade de São Paulo e cenário atual em Paris. Tese de Doutorado, Faculdade de Educação da USP.

Darmon, M. (2010). Domaines e approches. La socialisation politique (2a ed.). Paris: Armand Colin.

Dayrell, J. (2003, dezembro). O jovem como sujeito social. Revista Brasileira de Educação, 24, 40-52.

Dayrell, J., Gomes, N. L., \& Leão, G. (2010, dezembro). Escola e participação juvenil: é possível esse diálogo? Educar em Revista, 38,237-252.

Di Giovanni, J. R. (2003, dezembro). Jovens, feministas, em movimento: a Marcha Mundial das Mulheres no III Acampamento Intercontinental da Juventude. Estudos Feministas, 11(2), 655-660.

Facchini, R. (2011, junho). "Não faz mal pensar que não se está só”: estilo, produção cultural e feminismo entre as minas do rock em São Paulo. Cadernos Pagu, 36, 117-153.

Fernandes-Jesus, M., Cicognagni, E., \& Menezes, I. (2014, setembro/dezembro). Participação cívica e política: jovens imigrantes brasileiros/as em Portugal. Psicologia \& Sociedade, 26(3), 572-582.

Fillieule, O., \& Pudal, B. (2010). Sociologie du militantisme: problématisations et déplacement des méthodes d'enquête. Penser mouvements sociaux- conflits sociaux et contestations dans les societés contemporaines. Paris: La Découverte.

Florentino, R. (2008, junho). Democracia Liberal: uma novidade já desbotada entre jovens. Opinião Pública, 14(1), 205-235.

Fuks, M. (2011). Efeitos diretos, indiretos e tardios: Trajetórias da transmissão intergeracional da participação política. Lua Nova, 83, 145-178. 


\section{pro-posições}

http://dx.doi.org/10.1590/1980-6248-2016-0126

Fuks, M. (2012, junho). Atitudes, cognição e participação política: padrões de influência dos ambientes de socialização sobre o perfil político dos jovens. Opinião Pública, 18(1), 88-108.

Fuks, M., \& Pereira, F. B. (2011, junho). Informação e conceituação: a dimensão cognitiva da desigualdade política entre jovens de Belo Horizonte. Revista Brasileira de Ciências Sociais, 26(76), 123-143.

Gaxie, D. (2002). Appréhensions du politique et mobilisations des expériences sociales. Revue française de science politique, 52(2-3), 145-178.

Ihl, O. (2002). Socialisation et événements politiques. Revue française de science politique. 52(2-3), $125-144$.

Iriart, M. F. S., \& Bastos, A. C. de S. (2007, agosto). Uma análise semiótico-sistêmica de diferentes ecologias desenvolvimentais da juventude. Psicologia em estudo, 12(2), 239246.

Lugó, R. de S. (2014). Combatentes e revolucionários: processos de socialização de jovens integrantes de organizações que buscam a preservação ou a subversão da ordem. Dissertação de Mestrado em Educação, Universidade de São Paulo, São Paulo.

Maheirie, K., Groff, A. R., Bueno, G., Mattos, L. K. de, Silva, D. O. B. da, \& Müller, F. L. (2013, junho). Concepções de juventude e política: produção acadêmica em periódicos científicos brasileiros (2002 a 2011). Estudos de Psicologia, 18(2), 335-342.

Martins, F. A. S., \& Dayrell, J. T. (2013, dezembro). Juventude e participação: o grêmio estudantil como espaço educativo. Educação e Realidade, 38(4), 1.267-1.282.

Miranda, S. R., \& Freitas, D. P. de. (2013, junho). Brasil sob o signo da memória: notas sobre jovens, nação e nacionalismos. Educar em Revista, 29(2), 143-174.

Moreno, R. C., \& Almeida, A. M. F. (2009a, maio/agosto). "Isso é política, meu! ". Socialização militante e institucionalização dos movimentos sociais. Pro-Posições, $20(2), 59-76$.

Moreno, R. C., \& Almeida, A. M. F. (2009b, abril). O engajamento político dos jovens no movimento hip-hop. Revista Brasileira de Educação, 14(40), 130-142. 


\section{pro-posiçōes}

http://dx.doi.org/10.1590/1980-6248-2016-0126

Mortada, S. P. (2009). De jovem a estudante: apontamentos críticos. Psicologia \& Sociedade, 21(3), 373-382.

Muxel, A. (1997). Individu et mémoire familiale. Paris: Nathan Essais \& Recherches.

Muxel, A. (2001). L'expérience politiques des jeunes. Paris: Presses des Scieces Politiques.

Muxel, A. (2007). Chapitre 5 : Les jeunes et la politique. In P. Perrineau (Dir.), La politique en France et en Europe (pp. 123-153). Paris: Presses de Sciences Po (P.F.N.S.P.).

Muxel, A., \& Percheron, A. (1988). Histoires politiques de famille. Premières illustrations. Life Stories/Récits de Vie, 4.

Oppo, A. (2009). Socialização política. In N. Bobbio, N. Matteucci, \& G. Pasquino, Dicionário de Política (Vol. 2, 13a ed., pp.1.358). Brasília: Editora UnB.

Percheron, A. (1987, setembro). Socialisation et tradition: transmission e invention du politique. Pouvoirs, 42, 42-51.

Percheron, A. (1993). La socialization politique. Paris: Armand Colin.

Rios, R. R. (2009). Homofobia na perspectiva dos direitos humanos e no contexto dos estudos sobre preconceito e discriminação. In R. D. Junqueira (Org.), Diversidade sexual na Educação: problematizações sobre a homofobia nas escolas. Brasília: Ministério da Educação. Retirado em 2 de janeiro de 2016, de $<<$ http://unesdoc.unesco.org/images/0018/001871/187191por.pdf $>>$.

Schmidt, J. P. (2000). Juventude e política nos anos 1990: um estudo de socialização política no Brasil. Tese de Doutorado em Ciência Política, Universidade Federal do Rio Grande do Sul, Porto Alegre.

Simões, J. A., \& Facchini, R. (2009). Na trilha do arco-íris: do movimento homossexual ao LGBT. São Paulo: Editora Fundação Perseu Abramo.

Singer, A. (2013, novembro). Brasil, junho de 2013: classes e ideologias cruzadas. Novos Estudos CEBRAP, 97, 23-40.

Souza, J. (2012). Os batalhadores. Nova classe média ou nova classe trabalhadora? Belo Horizonte: Editora da UFMG. 


\section{pro-posições}

http://dx.doi.org/10.1590/1980-6248-2016-0126

Sposito, M. P. (2000). Algumas hipóteses sobre as relações entre movimentos sociais, juventude e educação. Revista Brasileira de Educação, 13, 73-94.

Sposito, M. P. (Coord.) (2009a). Estado da Arte sobre juventude na pós-graduação brasileira: educação, ciências sociais e serviço social (1999-2006) (Vol. 1). Belo Horizonte: Argvmentvm.

Sposito, M. P. (2009b). Estado da Arte sobre juventude na pós-graduação brasileira: educação, ciências sociais e serviço social (1999-2006) (Vol. 2). Belo Horizonte: Argvmentvm.

Sposito, M. P. (2010). Transversalidades no estudo sobre jovens no Brasil: educação, ação coletiva e cultura. Educação e Pesquisa, 36 (n. especial), 95-106.

Weller, W. (2005, abril). A presença feminina nas (sub)culturas juvenis: a arte de se tornar visível. Estudos Feministas, 13(1), 107-126.

Zibas, D. M. L., Ferretti, C. J., \& Tartuce, G. L. B. P. (2006, abril). Micropolítica escolar e estratégias para o desenvolvimento do protagonismo juvenil. Cadernos de Pesquisa, 36(127), p.51-85.

Submetido à avaliação em 29 de fevereiro de 2016, revisado em 09 de março de 2017, aceito para publicação em 31 de marco de 2017. 